\title{
CLOSE-RANGE IMAGING AND RESEARCH PRIORITIES IN EUROPE
}

\author{
P. Patias \\ The Aristotle University of Thessaloniki, GR, patias@auth.gr
}

Commission V, WG V/4

KEY WORDS: Close-range, imaging, metrology, cultural heritage, research, Horizon 2020, EU

\begin{abstract}
: research. Specific priorities, objectives and types of funded activities vary between funding periods. (2014-2020). H2020 is based on three pillars: (i) Excellent science, (ii) Industrial leadership, (iii) Societal challenges. leads researchers to search funds in the highly competitive transnational research instruments, as H2020.

This paper :

o draws the overall picture of Horizon 2020

o investigates the position of close-range imaging technologies, applications and research areas

o presents the research challenges in $\mathrm{H} 2020$ that offer funding opportunities in close-range imaging
\end{abstract}

Since 1984, the European Union's Framework Program for Research and Innovation has been the main instrument for funding

Horizon 2020 is the biggest EU Research and Innovation programme ever with nearly $€ 80$ billion of funding available over 7 years

The current economic crisis in Europe and elsewhere leads to extended shortage of research budgets in national levels, which in turn

\section{INTRODUCTION}

\subsection{Horizon $\mathrm{H2020}$ in brief}

Since 1984, the European Union's Framework Program for Research and Innovation has been the main instrument for funding research. Specific priorities, objectives and types of funded activities vary between funding periods.

The current economic crisis in Europe and elsewhere leads to extended shortage of research budgets in national levels, which in turn leads researchers to search funds in the highly competitive transnational research instruments, as $\mathrm{H} 2020$.

Horizon 2020 is the biggest EU Research and Innovation programme ever with nearly $€ 80$ billion of funding available over 7 years (2014-2020). H2020 is based on three pillars:

1. Excellent science

o European Research Council - Frontier research by the best individual teams

o Future and Emerging Technologies - Collaborative research to open new fields of innovation

o Marie Skłodowska-Curie actions - Opportunities for training and career development

o Research infrastructures (including e-infrastructure) Ensuring access to world-class facilities

2. Industrial leadership

o Leadership in enabling and industrial technologies (ICT, nanotechnologies, materials, biotechnology, manufacturing, space)

o Access to risk finance - Leveraging private finance and venture capital for research and innovation

o Innovation in SMEs - Fostering all forms of innovation in all types of SMEs
3. Societal challenges

o Health, demographic change and wellbeing

o Food security, sustainable agriculture and forestry, marine and maritime and inland water research and the bio-economy

o Secure, clean and efficient energy

o Smart, green and integrated transport

o Climate action, environment, resource efficiency and raw materials

o Europe in a changing world - Inclusive innovative and reflective societies

o Secure societies - Protecting freedom and security of Europe and its citizens

H2020 promotes a strong challenge-based approach, allowing applicants to have considerable freedom to come up with innovative solutions, since it provides: (a) Broader topics and (b) Strong emphasis on expected impact.

Before closing this introductory note, we must be fair: H2020 and FP7 are not the only available funding instrument in EU. Although they are the largest in budget and the most commonly referred to, there are other funding tools (eg. Interreg and MED programs, etc) that can support related activities.

\subsection{H2020 Research priorities and budget breakdown}

An overall budget breakdown for the next framework period is indicative of the research priorities underlying the H2020 concept.

From the Fig. 1 is clear that: (i) $32 \%$ is given to support the human scientific resources and the infrastructures in Europe as well as the mobility (Excellent Science), (ii) $23 \%$ is given to support mainly SMEs and their cooperation with the research institutes (Industrial Leadership), and (iii) $41 \%$ is given to main 
research body (Societal Challenges), which covers all known thematic areas (previously separated in FP7).

A closer look to this budget reveals further prioritization of the available funds. For example, $48 \%$ of the available funds for Excellent Science is routed towards the support of human research resources, while $68 \%$ of the available funds for Industrial Leadership is routed towards the support of SMEs to bring targeted research results quickly to market.

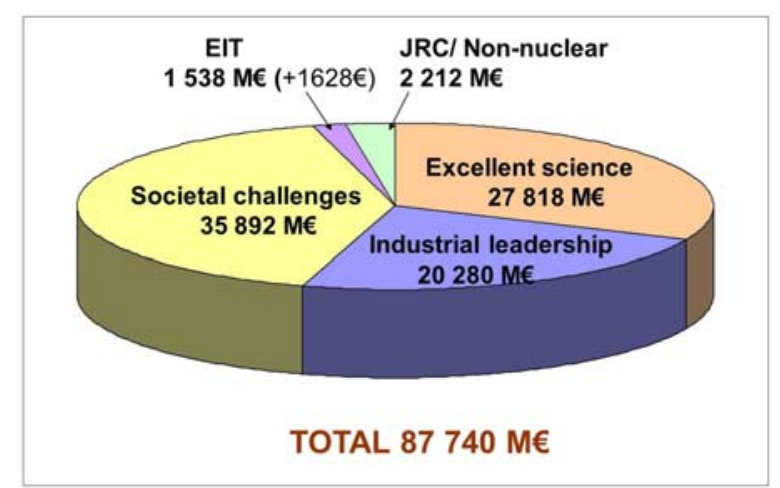

Figure 1. Horizon 2020 budget breakdown

To this end, it is worth noting that of the available funds for Societal Challenges $22 \%$ is routed towards Health issues, $11 \%$ towards Food, 16\% towards Energy, 19\% towards Transport, 9\% towards Environment, and 11\% towards Security. Of course, the above keywords are indicative and useful mainly for comparison to FP7 jargon. H2020 concept is addressing broader challenges that these.

Table 1. H2020 funding (period 2014-2020)

\begin{tabular}{|l|c|}
\hline Priority 1. Excellent Science & $13.3 \mathrm{M} €$ \\
\hline $\begin{array}{l}\text { European Research Council Frontier research } \\
\text { by the best individual teams }\end{array}$ & $3.1 \mathrm{M} €$ \\
\hline $\begin{array}{l}\text { Future and Emerging Technologies } \\
\text { Collaborative research to open new fields of } \\
\text { innovation }\end{array}$ & $5.6 \mathrm{M} €$ \\
\hline $\begin{array}{l}\text { Marie Curie actions Opportunities for training } \\
\text { and career development }\end{array}$ & $2.5 \mathrm{M} €$ \\
\hline $\begin{array}{l}\text { Research infrastructures } \\
\text { Ensuring access to world-class facilities }\end{array}$ & $13.8 \mathrm{M} €$ \\
\hline Priority 2. Industrial Leadership & $3.5 \mathrm{M} €$ \\
\hline $\begin{array}{l}\text { Leadership in enabling and industrial } \\
\text { technologies (ICT, nanotechnologies, } \\
\text { materials, biotechn., manufacturing, space) }\end{array}$ & $0.6 \mathrm{M} €+$ \\
\hline $\begin{array}{l}\text { Access to risk finance } \\
\text { Leveraging private finance and venture capital } \\
\text { for research and innovation }\end{array}$ & S. Ch) \\
\hline $\begin{array}{l}\text { Innovation in SMEs } \\
\text { Fostering all forms of innovation in all types of } \\
\text { SMEs }\end{array}$ & $8.8 \mathrm{M}$ (of \\
\hline Priority 3. Societal Challenges & $3.1 \mathrm{M} €$ \\
\hline Health, demographic change and wellbeing & $3.8 \mathrm{M} €$ \\
\hline $\begin{array}{l}\text { Food security, sustainable agriculture, marine } \\
\text { and maritime research \& the bio-economy }\end{array}$ & $5.8 \mathrm{M} €$ \\
\hline Secure, clean and efficient Energy & $6.8 \mathrm{M} €$ \\
\hline Smart, green and integrated Transport & $3.2 \mathrm{M} €$ \\
\hline $\begin{array}{l}\text { Climate action, resource efficiency and raw } \\
\text { materials }\end{array}$ & Inclusive, innovative and Secure societies \\
\hline
\end{tabular}

\section{DRAWING THE OVERALL PICTURE}

\subsection{Looking at the small picture}

The ISPRS "Close-range imaging" Scientific Society is mainly represented by Commission V. The regular bi-annual alternating symposia/congresses of Com. $\mathrm{V}$ provide a fair mapping of the critical mass of our society. In addition, CIPA symposia participants should be taken into account, noting that there is a good overlap of the two groups in issues of Cultural Heritage Documentation. Finally, the newly active group in UAV applications should be also considered, showing also an overlap with Com V activities.

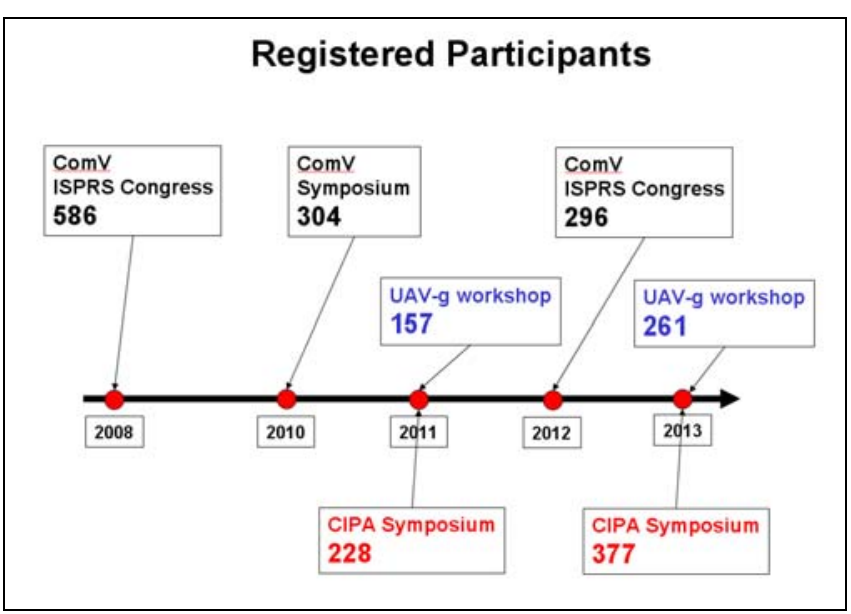

Figure 2. The critical mass of our "close-range imaging" society

All in all, looking back at the last years (Fig. 2), a decrease in participation to Com V symposia is observed, while a dedicated group of about 300 researchers exist. At the same time CIPA represents a more or less constant group of 300 researchers, with some sort of overlap to Com V group. Finally, worth mentioning is the increasing participation to UAV workshops over the last years.

The above picture is revealing on the "weight" the ISPRS closerange imaging group is having in the overall close-range imaging societies (eg. IEEE, SPIE, etc), which are collaborating but also competing to each other in the quest of the limited research funded globally.

\subsection{Looking at the big picture}

While internal assessment of the weight of our close-range imaging society ("scientific push") is revealing, it is even more useful to examine how the general public knows, understands and rates our activities. The latter can be considered as an indicator of the existing "market pull", which in turn may also influence and drive the political decisions on what research issues should be considered of high societal importance, leading in turn to setting the research priorities and the related budget breakdowns.

All these are easier said than done. Unfortunately, there exist no such surveys or mappings; at least not to my knowledge or publically available. The closest to this, one can imagine, holding all possible reservations on data quality, completeness, appropriateness, or measuring accuracy, is the tool of Google Trends. 
Google Trends is a public web facility of Google Inc., based on Google Search, which shows how often a particular search-term is entered relative to the total search-volume across various regions of the world, and in various languages (Wikipedia, http://en.wikipedia.org/wiki/Google_Trends).
We choose to search for the popularity of the terms "Imaging", "UAV", "Metrology", and "Close-range" as the most representatives and most used ones both by the scientific society and the public.

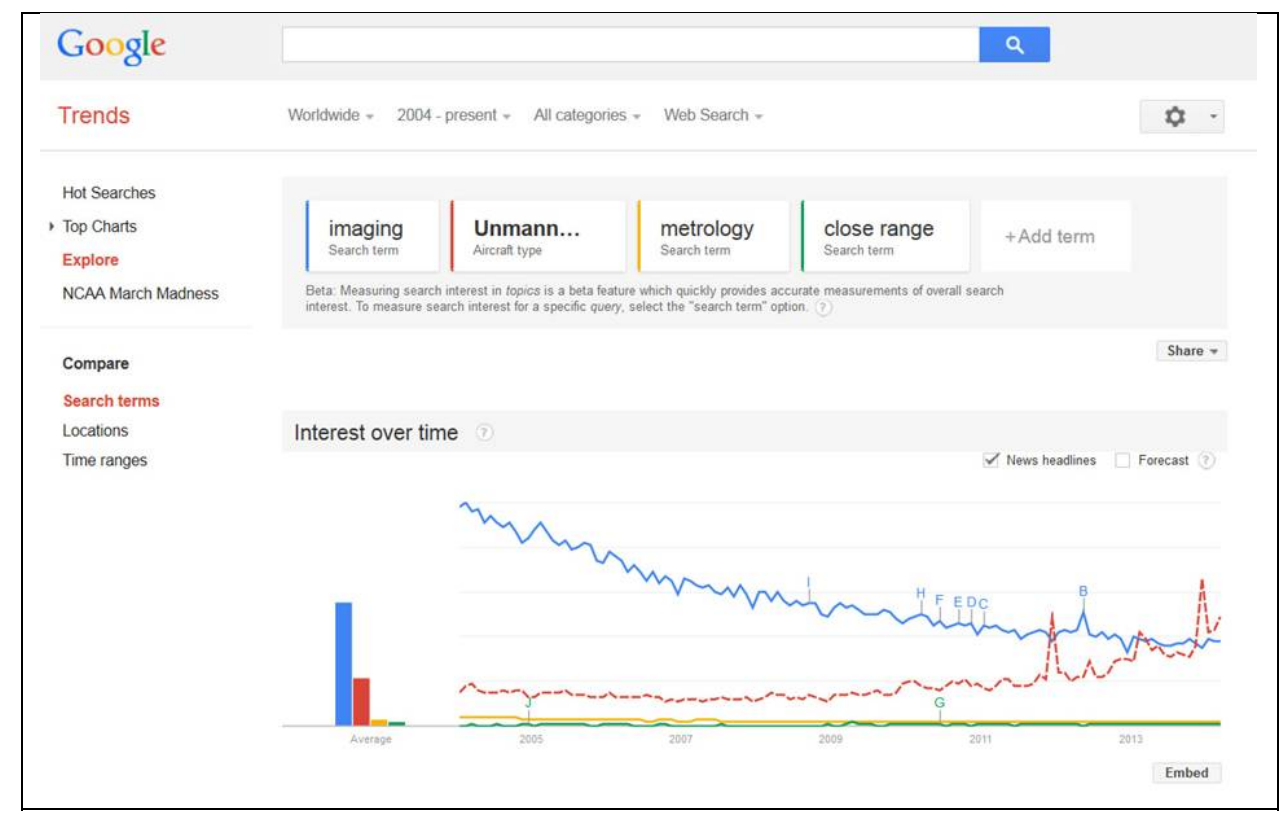

Figure 3. Examining the popularity of the terms "Imaging", "UAV", "Metrology", "Close-range"

It is very interesting to uncover the rather predictable fact that the terms "Metrology" or "Close-range" are rather unknown to the public, rarely used, and this is a general trend over the last years.

The terms "Imaging" and "UAV" are rather well-used, the first one almost three times more frequently than the second one at average. However, there exists a clear steeply decreasing trend in the popularity of the term "Imaging" at the last ten years, while a remarkable increasing of the popularity of the term "UAV" is overpassing it.

What is even more remarkable is the fact that this trend is very much correlated to the observed fluctuation in registered participation in ISPRS activities (see Fig. 2)!

\subsection{Looking back: Funded projects under the previous Framework Program (FP7)}

A useful survey of the research projects funded under the FP7 for the period 2007-2013, is presented in Table 2 [URL1]. The effort focuses only at the projects having the keywords "Imaging", "UAV", "Metrology" or "Close-range" as well the term "Cultural Heritage" in their titles.

Table 2. EU FP7 funded Projects - In detail

\begin{tabular}{|c|c|c|c|}
\hline $\begin{array}{l}\text { Key } \\
\text { word }\end{array}$ & $\begin{array}{c}\text { FP7 } \\
\text { Program }\end{array}$ & $\begin{array}{l}\text { Budge } \\
\text { t (M€) }\end{array}$ & Project title \\
\hline \multirow{3}{*}{$\begin{array}{l}\stackrel{0}{\Xi} \\
\stackrel{\Xi}{00} \\
\underset{\Xi}{\Xi} \\
\Xi \\
\Xi\end{array}$} & IDEAS & 1.4 & $\begin{array}{l}\text { Ultrafast Imaging of the Heart Using Ultra- } \\
\text { sound: a breakthrough for early diagnosis } \\
\text { of cardiac diseases }\end{array}$ \\
\hline & IDEAS & 1.5 & Phase contrast X-ray imaging for medicine \\
\hline & IDEAS & 2.0 & $\begin{array}{l}\text { Combined time domain and spectral } \\
\text { domain coherence gating for imaging and } \\
\text { bio sensing }\end{array}$ \\
\hline
\end{tabular}

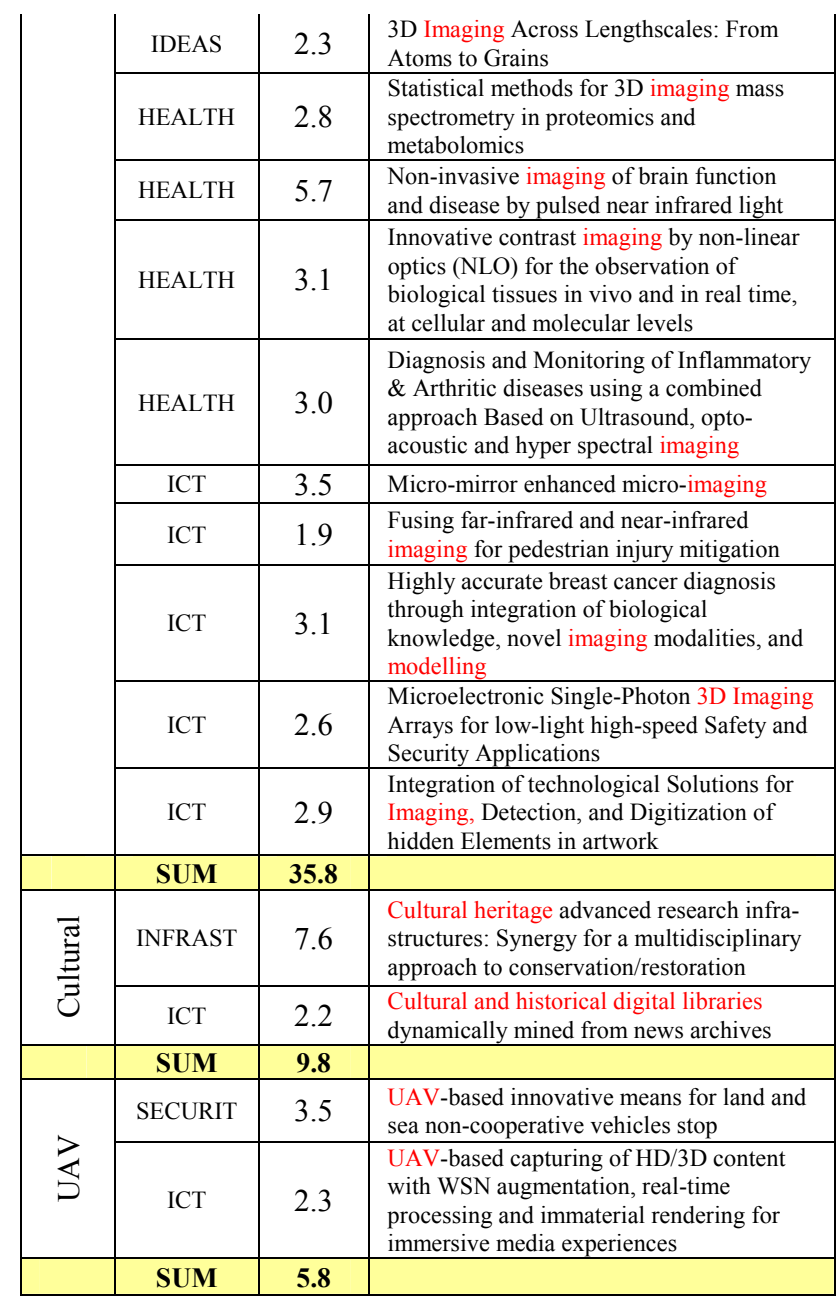


Table 3. EU FP7 funded Projects - General

\begin{tabular}{|c|c|c|c|}
\hline \multirow{2}{*}{ Keyword } & Program & $\begin{array}{c}\text { Budget } \\
\text { (M€) }\end{array}$ & $\begin{array}{c}\text { No. of funded } \\
\text { projects }\end{array}$ \\
\hline \multirow{3}{*}{ Imaging } & IDEAS & 7.2 & 4 \\
\cline { 2 - 4 } & HEALTH & 14.6 & 4 \\
\cline { 2 - 4 } & ICT & 14.0 & 5 \\
\hline \multirow{2}{*}{ cultural } & TOTAL & $\mathbf{3 5 . 8}$ & $\mathbf{1 3}$ \\
\hline & INFRASTRUCTURE & 7.6 & 1 \\
\cline { 2 - 4 } & ICT & 2.2 & 1 \\
\hline \multirow{2}{*}{ UAV } & TOTAL & $\mathbf{9 . 8}$ & $\mathbf{2}$ \\
\cline { 2 - 4 } & SECURITY & 3.5 & 1 \\
\hline \multicolumn{2}{|c|}{ ICT } & 2.3 & 1 \\
\hline close range & TOTAL & $\mathbf{5 . 8}$ & $\mathbf{2}$ \\
\hline metrology & & & $\mathbf{0}$ \\
\hline terrestrial modelling & & $\mathbf{0}$ \\
\hline
\end{tabular}

Summing up, it is revealing that during the period 2007-2013 (Table 3, Fig. 4):

- 13 projects in "Imaging" have been funded with $35.8 \mathrm{M} €$, mainly in HEALTH and ICT. This actually covers $70 \%$ of the whole budget used in all related activities.

- 2 projects in "Cultural Heritage" have been funded with 9.8M€, mainly in INFRASTRUCTURE and ICT

- 2 projects in "UAV" have been funded with 5.8M€, mainly in SECURITY and ICT

- No projects have been funded with the terms "closerange", "metrology", or "terrestrial modelling"

- HEALTH and ICT are the main application areas funded

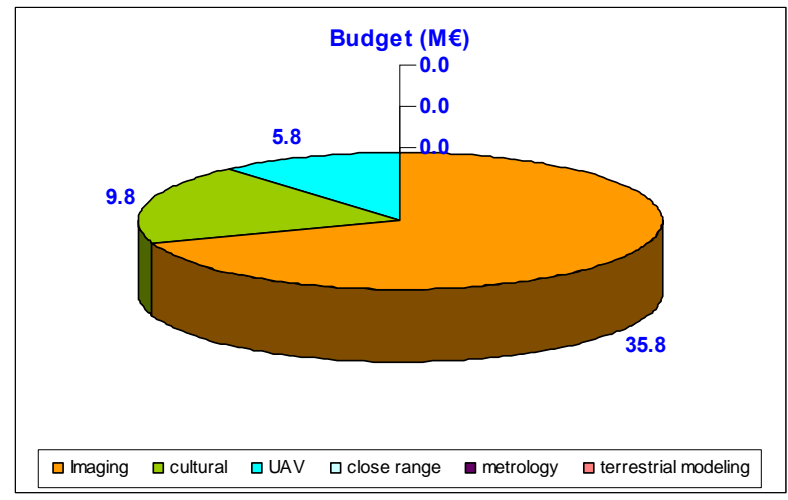

Figure 4. EU FP7 funded Projects

In Fig. 5 we present an interesting "mapping" of the internal structure of the network of the funded projects. The big circles show the checked categories "Imaging", "UAV" and "Cultural Heritage"). The small circles represent the acronym of the funded project and the origin country of the coordinator. The lines represent the different partners for each project, while the color represents the FP7 program, within which the project has been funded.

\section{Direct conclusions are that :}

o ITALY, is the origin of the coordinators of the most funded projects. This is twice higher than the followers: SPAIN, FRANCE, UK, GERMANY and AUSTRIA.

o Project consortia in ICT and SECURITY are generally larger than in HEALTH

\section{FP7 PROGRAM}
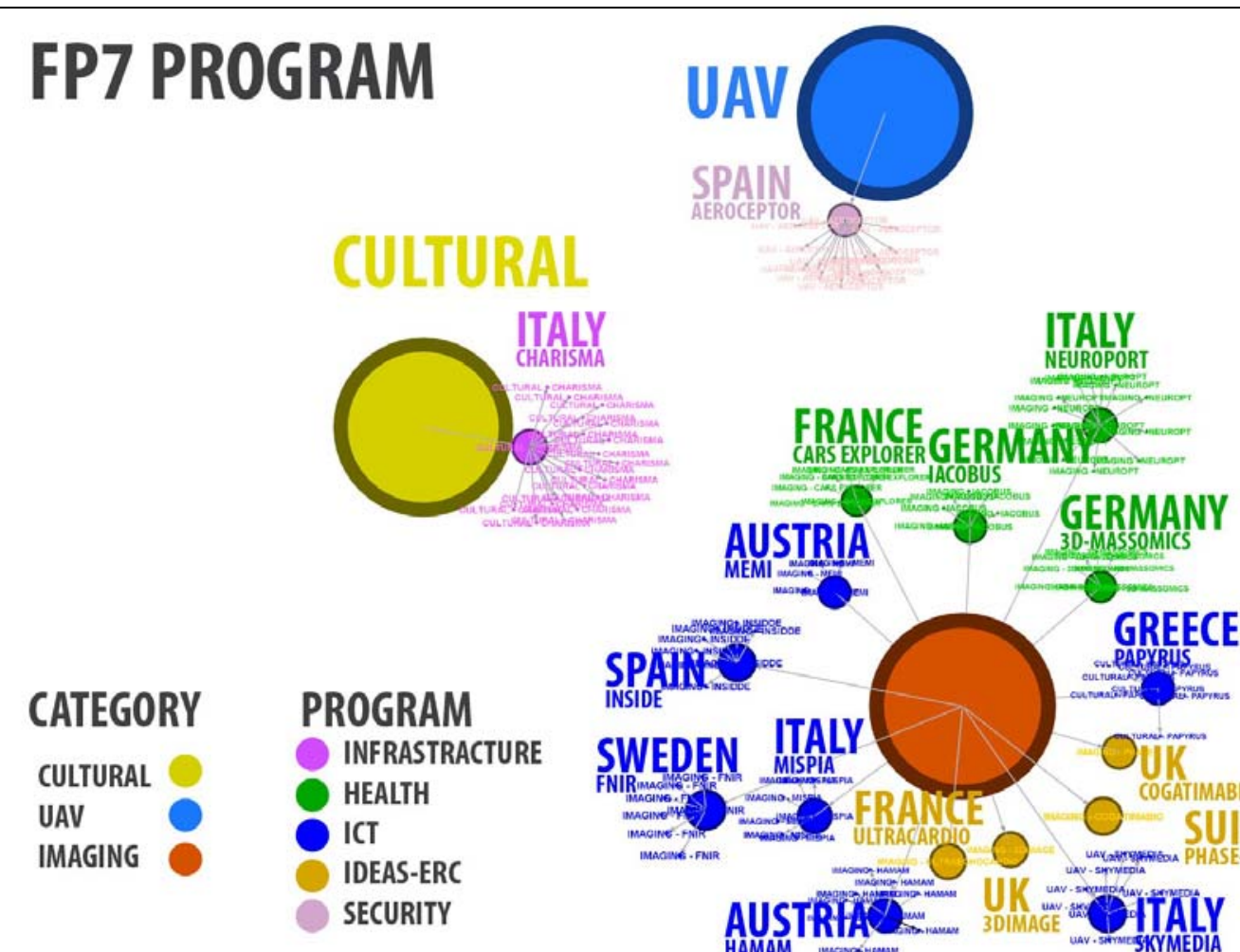

GREECE

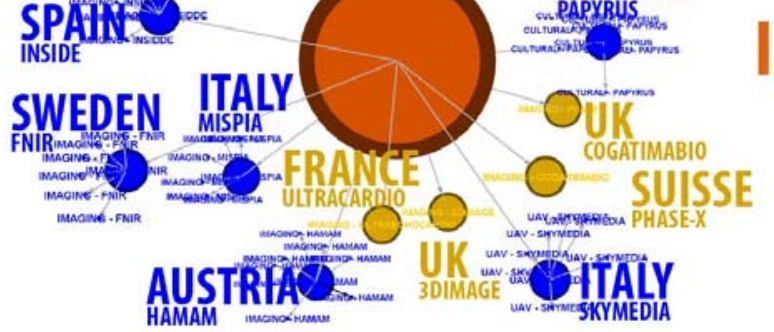

Figure 5. Network analysis of the funded FP7 projects along with the stakeholders and the coordinator origin 


\section{RESEARCH CHALLENGES \& FUNDING OPPORTUNITIES IN H2020 2014/2015}

The Horizon 2020 framework program will support the research in European countries for the next seven years. Although the overall budget breakdown has been decided, the specific breakdown in more detailed form is only known for the first two years (2014 and 2015), after the December 2013 publication of the first open calls.

In an effort to highlight the funding opportunities in "imaging" activities we searched for this keyword in the titles of the open calls for this period and more specifically in the (a) Societal Challenges and the (b) Industrial Leadership pillars, which are the main funding tools for research [URL2].

In Table 4 and Fig. 6 the total budget as well as the related to "imaging" activities budget is shown.

Table 4. H2020 2014/2015 calls related to "imaging" activities

\begin{tabular}{|c|c|c|c|c|c|}
\hline \multirow{2}{*}{ 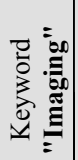 } & \multirow{2}{*}{ Program } & \multicolumn{2}{|c|}{$\begin{array}{c}\text { total } \\
\text { Budget (M€) }\end{array}$} & \multicolumn{2}{|c|}{$\begin{array}{c}\text { related } \\
\text { Budget (M€) }\end{array}$} \\
\hline & & 2014 & 2015 & 2014 & 2015 \\
\hline 6 & $\begin{array}{l}\text { Health, demographic } \\
\text { change and wellbeing }\end{array}$ & 549.0 & 537.0 & 48.0 & 164.6 \\
\hline 0 & $\begin{array}{l}\text { Secure, clean and } \\
\text { efficient energy }\end{array}$ & 504.0 & 214.0 & 0.0 & 0.0 \\
\hline 0 & $\begin{array}{l}\text { Climate action, } \\
\text { environment, resource } \\
\text { efficiency and raw } \\
\text { materials }\end{array}$ & 292.0 & 343.0 & 0.0 & 0.0 \\
\hline 0 & $\begin{array}{l}\text { Europe in a changing } \\
\text { world - inclusive, } \\
\text { innovative and } \\
\text { reflective Societies }\end{array}$ & 37.0 & 51.5 & 14.0 & 25.5 \\
\hline 4 & $\begin{array}{l}\text { Secure societies - } \\
\text { Protecting freedom and } \\
\text { security of Europe and } \\
\text { its citizens }\end{array}$ & 116.8 & 128.4 & 40.8 & 64.4 \\
\hline 1 & $\begin{array}{l}\text { Food Security, } \\
\text { sustainable agriculture } \\
\text { and forestry, marine } \\
\text { and maritime inland } \\
\text { water research and the } \\
\text { bio-economy }\end{array}$ & 259.9 & 201.0 & 34.0 & 18.0 \\
\hline 3 & $\begin{array}{l}\text { Leadership in enabling } \\
\text { and industrial } \\
\text { technologies / iii. } \\
\text { SPACE }\end{array}$ & 205.8 & 232.9 & 40.0 & 51.0 \\
\hline 0 & $\begin{array}{l}\text { Leadership in enabling } \\
\text { and industrial } \\
\text { technologies /i. ICT }\end{array}$ & 805.3 & 893.1 & 40.0 & 39.0 \\
\hline
\end{tabular}

Several observations are justified from the above data:

o HEALTH, SECURITY, SPACE and ICT are the areas where "imaging" is met more often

o more than $200 \mathrm{M} €$ will be devoted in "imaging" activities in HEALTH

o more than $100 \mathrm{M} €$ will be devoted in "imaging" activities in SECURITY

o more than $80 \mathrm{M} €$ will be devoted in "imaging" activities in ICT

o there are funding opportunities for "imaging" in "Cultural Heritage" of about $50 \mathrm{M} €$
0 there are further opportunities in FOOD and SPACE of about $150 \mathrm{M} €$
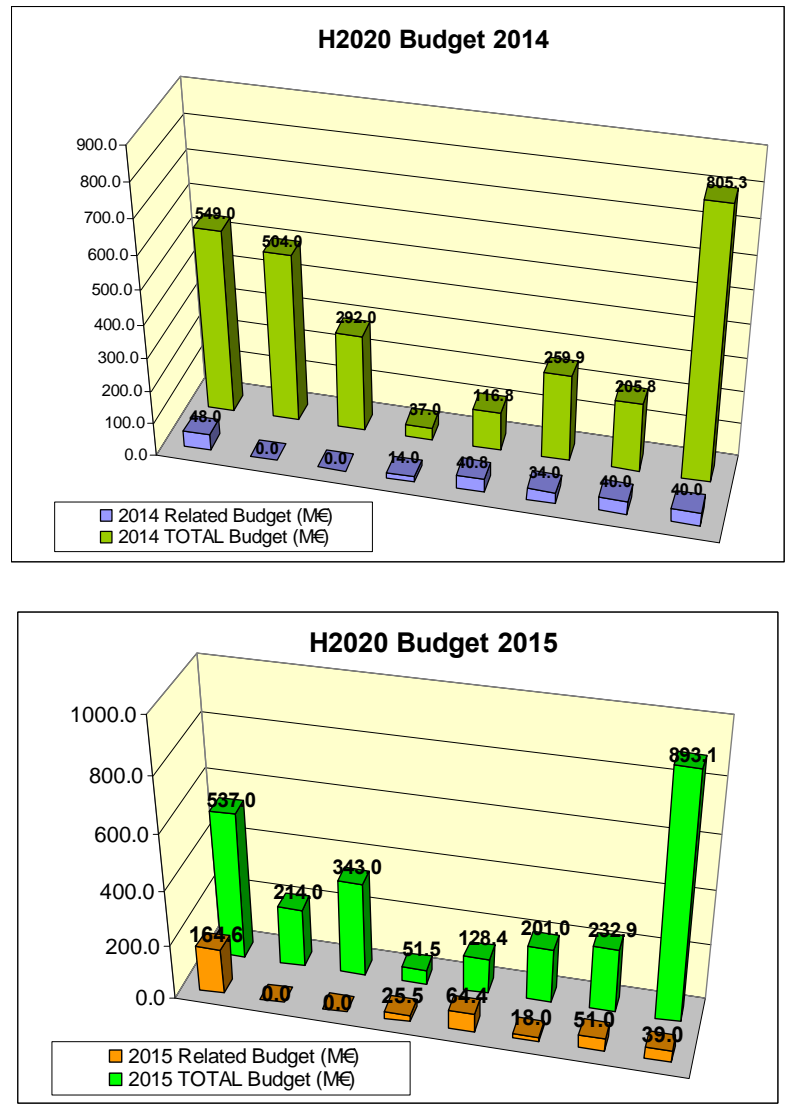

Figure 6. H2020 2014/2015 calls related to "imaging" activities

\section{CONCLUSIONS}

From the above data, the main conclusions that can be drawn are the following:

During the EU FP7 framework program (period 2007-2013):

- HEALTH and ICT are the main application areas of "Imaging" that have been funded

- INFRASTRUCTURE and ICT are the main application areas of "Cultural Heritage" that have been funded

- SECURITY and ICT are the main application areas of "UAV" that have been funded

For the EU H2020 framework program (period 2014-2020):

- HEALTH, SECURITY, SPACE and ICT are the areas where "imaging" is met more often

- The total budget devoted for related projects in "imaging" sector is multiple times higher in $\mathrm{H} 2020$ than before

Therefore, it seems that HEALTH and ICT the major "stakeholders" for "Imaging", while SECURITY plays an increasing role for "Imaging" and "UAV".

During the last period "Imaging" is getting out of trend as far as general public concerns, "UAV" is increasingly trendy, whereas "Close-range" and "Metrology" is steadily unknown to the public. This is notably correlated by the funding history of FP7 since no projects have been funded with the terms "closerange", "metrology", or "terrestrial modelling". 
A direct conclusion is that our scientific society should "rephrase" its focus and scientific contribution keywords in more trendy terms. This will mark a symbolic change to more popular and publically recognizable application foci.

It is important to note also that in H2020 there are also opportunities in the areas of FOOD and SPACE for application of imaging techniques. These areas are non-conventional applications areas and traditionally imaging techniques have not been used extensively. Therefore, it is very promising that new applications areas are opening to our scientific society, which should be alerted by this and should be benefited by this increasing pull for knowledge transfer.

A final remark concerns the underlying changing character of funded research. It seems that cooperation on a national level is "discouraged", since there is a clear promotion of inclusion of few only partners per country, whereas the geographical distribution of partners is almost mandatory and the cooperation on a European level is highly "encouraged".

On the other hand, while in principle the International cooperation in European Neighborhood is supported, the International cooperation with USA/AUSTRALIA/JAPAN is problematic. At the same time, third countries (like Switzerland, China, Russia or Brazil) previously supported in such projects, are no longer considered as European priorities.

At last, the network analysis revealed that ITALY, is the origin of the coordinators of the most funded projects. This is twice higher than the followers: SPAIN, FRANCE, UK, GERMANY and AUSTRIA. In addition, it seems that project consortia in ICT and SECURITY are generally larger than in HEALTH.

\section{REFERENCES}

URL1 - CORDIS search [http://www.cordis.europa.eu/search]

URL2 - H2020 [http://ec.europa.eu/research/horizon2020] 